\title{
La constitución económica de la Unión Europea y el difícil equilibrio entre las libertades económicas y los derechos sociales ${ }^{1}$
}

\author{
Santiago Larrazabal Basañez \\ Universidad de Deusto
}

Recibido: 16.06 .10

Aceptado: 29.06 .10

Sumario: I. Introducción.-II. Una perspectiva doctrinal.-III. Una perspectiva jurisprudencial. 1. Sentencia de 11 de diciembre de 2007 (Viking Line). 2. Sentencia de 18 de diciembre de 2007 (Laval un Partneri). 3. Sentencia de 3 de abril de 2008 (Rüffert). 4. Sentencia de 19 de junio de 2008 (Comisión contra Luxemburgo).-IV. Reflexión final.-V. Bibliografía.-VI. Jurisprudencia seleccionada del Tribunal de Justicia de la Unión Europea en materia de libertades económicas y derechos sociales. 1. Aplicabilidad del Tratado, libre circulación de personas y actividades sindicales. 2. Derechos fundamentales entendidos como interés legítimo que pueden justificar restricciones de obligaciones impuestas por el derecho comunitario. 3. Extensión de la legislación o de los convenios colectivos relativos a toda persona que realice un trabajo por cuenta ajena en el territorio de un Estado miembro, con independencia del Estado de establecimiento del empresario, siempre que no vayan más allá de garantizar el objetivo perseguido: la protección de los trabajadores desplazados. 4. Derecho a adoptar medidas de conflicto colectivo para proteger a los trabajadores del Estado de acogida frente a una eventual política de «dumping social», como razón imperiosa de interés general que justifique restricciones a una libertad fundamental garantizada por el Tratado. 5. Conflicto entre las libertades comunitarias de establecimiento y de circulación de servicios y los derechos sociales de los trabajadores de los Estados miembros.

Resumen: El autor analiza algunos contenidos básicos de lo que se ha dado en llamar la Constitución Económica Europea y el conflicto que se plantea entre las libertades económicas y los derechos sociales en el ámbito de la

1 Este texto reformula y amplía mi intervención en el VIII Simposio sobre la Cultura Económica Vasca que, bajo el título de « Crisis e intercooperación» fue organizado conjuntamente por el Instituto de Estudios Vascos de la Universidad de Deusto, la Asociación Internacional de Derecho Cooperativo y la Academia Vasca de Derecho y tuvo lugar en Bilbao el 14 de diciembre de 2009. 
Unión Europea, y advierte de que las últimas tendencias normativas y jurisprudenciales comunitarias parecen primar de manera excesiva las primeras en detrimento de los segundos, con el peligro que ello supone para la consolidación de una auténtica Europa social y el creciente desapego de una ciudadanía que ve cómo se avanza firmemente en el ámbito de la Unión Económica y Monetaria, mientras la Europa social avanza muy lentamente y a veces da preocupantes muestras de parálisis o incluso de cierto retroceso.

Palabras-clave: Unión Europea, Constitución Económica, Libertades Económicas, Derechos sociales, «dumping social», medidas de conflicto colectivo.

Abstract: The author examines some basic contents of what has come to be known as the European Economic Constitution and the conflict raised between economic freedoms and social rights within the European Union. $\mathrm{He}$ also warns that in the latest trends in EU legislation and jurisprudence, the former seem to take excessive priority over the latter. This may jeopardise the consolidation of a genuine social Europe and the increasing indifference of citizens, who see how firm steps are being taken within the Economic and Monetary Union while social Europe is slowly moving forward, and often shows worrying signs of paralysis, or even some backward movement.

Key words: European Union, Economic Constitution, Economic Freedoms, Social Rights, social dumping, collective conflict measures. 


\section{Introducción}

En los últimos tiempos he defendido que los estudiosos del Derecho Constitucional deberíamos dedicar más atención al estudio de la Constitución Económica, donde se plasman el modelo económico, los principios rectores de la política social y económica y los derechos económicos y sociales, con el objetivo de ir más allá de una democracia formal y avanzar hacia una democracia material. En el VII Simposio sobre la Cultura Económica Vasca, correspondiente a 2008, tuve ocasión de acercarme al estudio de la Constitución Económica española desde la óptica de los valores de la cultura económica del movimiento cooperativo ${ }^{2}$. En este VIII Simposio de 2009, me he decantado por acercarme a lo que podríamos llamar la «Constitución Económica de la Unión Europea», dado que el Tratado de Lisboa ha entrado en vigor el 1 de diciembre de 2009, prestando una especial atención al difícil equilibrio entre las libertades económicas que ésta consagra y los derechos sociales y económicos recogidos en la Carta de Derechos, que desde la entrada en vigor del Tratado de Lisboa tiene el mismo valor que los Tratados.

En un momento de crisis económica como la que estamos padeciendo, en un contexto de globalización, el análisis de la Constitución Económica de la Unión Europea y de lo que ha ocurrido hasta ahora con la aplicación de los derechos sociales, nos permite analizar de cerca algunos de los aciertos y errores de la construcción europea. Comenzaré analizando el tema desde una perspectiva doctrinal, para continuar con el análisis de la jurisprudencia del Tribunal de Justicia en la materia, centrado esta vez en cuatro Sentencias que parecen estar marcando una clara tendencia, lo que me llevará a una breve conclusión, o casi mejor, reflexión final, acompañada de las obligadas referencias bibliográficas y de una selección de Sentencias del Tribunal de Justicia.

\section{Una perspectiva doctrinal}

Desde el 1 de diciembre de 2009, tras el fracaso del Tratado Constitucional Europeo y después de un tortuoso y larguísimo proceso de ratificación por todos los Estados miembros de la Unión Europea, ha entrado en vigor la última modificación de los Tratados constitutivos de la

2 Larrazabal Basañez, S., «Constitución económica, Democracia social, Innovación y Cultura Económica del Cooperativismo Vasco». Boletín de la Asociación Internacional de Derecho Cooperativo. 2009, n. ${ }^{\circ} 43$, pp. 179-191. 
Unión Europea, el denominado «Tratado de Lisboa», firmado en la capital portuguesa el 13 de diciembre de 2007 y con él la Carta de los Derechos Fundamentales de la Unión Europea de 7 de diciembre de 2000, tal y como fue adoptada en Estrasburgo el 12 de diciembre de 2007, es ya jurídicamente vinculante y tiene el mismo valor jurídico que los Tratados, según establece el art. $6 .^{\circ}$ del Tratado de la Unión Europea en la nueva redacción dada a éste por el Tratado de Lisboa. Este es el nuevo marco normativo ante el que nos encontramos a la hora de analizar el asunto del difícil equilibrio entre libertades económicas y derechos sociales.

En relación con la Carta de los Derechos Fundamentales, ésta introduce un novedoso Título IV, bajo la denominación de "Solidaridad», donde se recogen los denominados derechos sociales y económicos como, por ejemplo, los derechos a la información y consulta de los trabajadores en la empresa, el derecho de negociación y de acción colectiva, el derecho de acceso a los servicios de colocación, la protección en caso de despido injustificado, el derecho a unas condiciones de trabajo justas y equitativas, la prohibición del trabajo infantil y la protección de los jóvenes en el trabajo, la garantía de la conciliación entre la vida familiar y laboral, la Seguridad social y ayuda social, el derecho a la protección de la salud, el acceso a los servicios de interés económico general, la protección del medio ambiente o la protección de los consumidores.

Como establece el artículo 51 de la Carta, sus disposiciones están dirigidas a las instituciones, órganos y organismos de la Unión, dentro del respeto del principio de la subsidiariedad, así como a los Estados miembros, únicamente cuando apliquen el Derecho de la Unión y no amplía el ámbito de aplicación del Derecho de la Unión más allá de las competencias de ésta, ni crea ninguna competencia o misión nuevas para la Unión, ni modifica las competencias y misiones definidas en los Tratados. Y además, hay que tener en cuenta que algunos Estados han logrado que al Tratado de Lisboa se le añada un Protocolo sobre la aplicación de la Carta de los Derechos Fundamentales de la Unión Europea —es el caso de Polonia y Reino Unido- donde se excluye expresamente la aplicación del título IV de la Carta (es decir, el que recoge los derechos relativos a la «solidaridad») en dichos países. ${ }^{3}$

3 El artículo 1.2. de dicho Protocolo dice literalmente: «En particular, y a fin de no dejar lugar a dudas, nada de lo dispuesto en el título IV de la Carta crea derechos que se puedan defender ante los órganos jurisdiccionales de Polonia o del Reino Unido, salvo en la medida en que Polonia o el Reino Unido hayan contemplado dichos derechos en su legislación nacional». 
En lo que se refiere al Tratado de Lisboa, se podría decir que no han cambiado mucho las cosas en la difícil relación entre las libertades económicas y los derechos sociales en el ámbito de la Unión Europea, que se parece inclinarse claramente por favorecer las primeras en detrimento de los segundos. Como ha escrito Gonzalo MAESTRO BUELGA:

El Tratado de Lisboa persiste en una relación asimétrica entre dimensión económica y social que confina, a esta última, a un papel marginal en una posición de subordinación funcional al mercado, rompiendo con la tradición del constitucionalismo social europeo. (...) El mercado y la competencia disuelven a la política social e impiden hablar de Derechos sociales, sin los que no se puede afirmar la ciudadanía social. El impulso público de la competencia y el mercado como principios absolutos impone la exclusión del status constitucional de los Derechos sociales propio del constitucionalismo social, desnaturalizando el papel constitucional del espacio social en el ordenamiento europeo. El nuevo compromiso del poder público en la tutela de la autonomía del mercado que incorpora el constitucionalismo económico europeo se configura como límite a la afirmación de la ciudadanía social. ${ }^{4}$

Y el problema, como ha puesto de manifiesto este autor, es que la Constitución económica europea sigue definiéndose desde el mercado, y no sólo coloca a la dimensión social en una posición subalterna, sino que además extiende este modelo a las constituciones económicas de los Estados miembros. En sus propias palabras:

... La Constitución europea, cuyo núcleo sigue siendo económico, transforma el constitucionalismo estatal vinculado a la forma «Estado social», desnaturalizándolo. Sanciona así, el tránsito a una nueva forma, la del «Estado mercado». ${ }^{5}$

Como ha escrito CANTARO ${ }^{6}$, "es el principio de la economía de mercado quien constituye el verdadero faro de la acción de la comunidad, de la que es criterio y fin esencial». En opinión de GÁLVEZ7 , en la

4 Maestro Buelga, G. "Constitución económica y modelo social europeo». Boletín de la Academia Vasca de Derecho. 2008, n. ${ }^{\circ} 15$, pp. 51 y 74.

5 Maestro Buelga, G. «Constitución económica...», op. cit., p. 79.

6 Cantaro, A. «El declive de la Constitución económica del Estado Social». En García Herrera, M.A. (dir.). El constitucionalismo en la crisis del Estado Social. Bilbao: Universidad del País Vasco / Euskal Herriko Unibertsitatea, 1997, p. 172.

7 Viera Álvarez, Ch. La libertad de empresa y algunos límites desde la perspectiva del Estado Social. Memoria académica para la obtención del Diploma de Estudios Avanzados por la Universidad de Deusto, noviembre de 2009 (inédita), pp. 34-41. 
Unión Europea la definición de la Constitución económica se realiza en torno a la tensión entre los objetivos económicos y sociales, existiendo una clara falta de disposiciones sociales en los textos de los tratados constitutivos. Desde su constitución, la Comunidad estableció espacios de actuación diferenciada, confiando el ámbito social a los Estados miembros, que se convierten en el espacio de realización del Estado social, y a la Comunidad el ámbito económico, que se configura como el de mercado, de tal manera que ambos espacios aparecen como confrontados y portadores de lógicas diferentes. Podría hablarse, en su opinión, de vínculo social e intervención como criterios de la constitución económica del Estado social, frente a mercado y liberalización.

Y siguiendo a CANCIO MELIÁ ${ }^{8}$, describe las notas más relevantes de la Constitución económica europea, que podrían ser las siguientes:

a) El establecimiento de un mercado interior de matriz neoliberal, cuyas normas fundamentales son las garantías de las libertades comunitarias, del derecho de la competencia y la aprobación de progresivas medidas de liberalización.

b) La adopción de una política monetaria, neoliberal-monetarista, con el objetivo fundamental de mantener la estabilidad de los precios, lo que supone precios estables, finanzas públicas y condiciones monetarias sólidas y balanzas de pagos estables.

c) La limitación de las políticas de gasto e ingresos mediante la coordinación de la política económica y de la política de empleo, siendo el núcleo del sistema el cumplimiento de los objetivos de la política monetaria común.

d) La falta de un catálogo jurídicamente vinculante de derechos sociales (si bien habría que matizar esta afirmación viendo la evolución que tenga el cumplimiento y la eficacia real de los derechos sociales recogidos en la Carta de Derechos fundamentales) ${ }^{9}$, con una devaluación de los derechos sociales potencialmente existentes de conformidad con las Constituciones de los Estados miembros.

La experiencia que hemos tenido hasta ahora es que, en general, las políticas comunitarias han sido, como ha escrito ALBERTí ROVIRA ${ }^{10}$, po-

8 Cancio Meliá, J. «La Constitución económica: promesas incumplibles». Revista Jurídica de la Universidad Autónoma de Madrid. 2002, n. ${ }^{\circ}$, pp. 92 y ss.

9 El texto del paréntesis es mío.

10 Albertí Rovira, E. «La Constitución económica. Tendencias a los veinte años de la Constitución». En Trujillo, G. et al. La experiencia constitucional. Madrid: Centro de Estudios Políticos y Constitucionales, 2000, p. 136. 
líticas de liberalización de mercados y de apoyo a la integración económica de las naciones. Mientras en muchos estados miembros la libertad de empresa y la competencia estaban compensadas por la intervención del Estado para garantizar la efectividad de los derechos sociales en el marco del Estado Social de Derecho que sus respectivas Constituciones consagran, en el ámbito de la Unión Europea no existe esa intervención para contrapesar de algún modo la fuerza expansiva que las normas sobre competencia, libertades de establecimiento, circulación, etc. tienen. Esa sensibilidad no aparece ni en la legislación ni tampoco, como veremos enseguida, en la jurisprudencia del Tribunal de Justicia. Y además, como bien ha señalado URIARTE TORREALDAY ${ }^{11}$, el establecimiento del mercado único va a determinar la limitación de algunas potestades de intervención del Estado sobre el mercado de las que éste disponía tradicionalmente y que podían ejercitar esa función de contrapeso y reequilibrio entre las libertades económicas y los derechos económicos y sociales.

Este mismo autor ${ }^{12}$ ha señalado cómo aunque el Tratado de Lisboa contempla en el Título $X$ un apartado de política social y aunque los siguientes Títulos tienen contenido social, el tipo de lenguaje utilizado en ellos no es tan imperativo como el utilizado en las disposiciones económicas. Veamos un ejemplo: el texto del artículo 151 cuando afirma que:

La Unión y los Estados miembros... tendrán como objetivo el fomento del empleo, la mejora de las condiciones de vida y de trabajo, a fin de conseguir su equiparación por la vía del progreso, una protección social adecuada, el diálogo social, el desarrollo de los recursos humanos para conseguir un nivel de empleo elevado y duradero y la lucha contra las exclusiones. A tal fin la Unión y los Estados miembros emprenderán acciones en las que se tenga en cuenta la diversidad de las prácticas nacionales, en particular en el ámbito de las relaciones contractuales, así como la necesidad de mantener la competitividad de la economía de la Unión.

El lenguaje utilizado nos ilustra perfectamente acerca de las intenciones del legislador: incluso en un artículo como el 151, referido expresamente a la política social, frente al objetivo del «fomento» del empleo, redactado en términos de deseo, apoyo, promoción, etc., aparece inmediatamente un objetivo económico fundamental redactado no en términos de deseo y promoción, sino en términos claramente im-

11 Uriarte Torrealday, R. «Propiedad, libre empresa y trabajo: los derechos económicos en la Constitución español y en el proyecto constitucional europeo». Revista de Derecho Constitucional Europeo. 2005, n. ${ }^{\circ} 4$, p. 341.

12 Uriarte Torrealday, R. Ibidem, p. 344. 
perativos: la necesidad de mantener la competitividad de la economía de la Unión. La diferencia de trato entre ambos elementos es tan evidente que incluso el lenguaje es distinto y lo mismo ocurre con los artículos que siguen a éste, donde el legislador vuelve a emplear fórmulas etéreas y llenas de buenas intenciones (habla de promover, procurar, apoyar, fomentar...) pero no va más allá. ${ }^{13}$

Todo esto no es sino un elemento más que nos lleva a constatar cómo la Unión económica y monetaria avanza a paso rápido, mientras la Europa social lo hace a paso de tortuga. Una vez más, se cumple aquel dicho de Napoleón: «nos batimos más por nuestros intereses que por nuestros derechos», y la Europa Social y los derechos sociales son el pariente pobre de la orgullosa familia europea. Hay algunos países de la Unión que expresamente han dicho que no desean avanzar mucho más en la Europa Social ( $y$, como hemos visto, han exigido incluso quedar exentos de la aplicación de los derechos sociales recogidos en la Carta) y hay otros que aunque no lo digan así de claro, piensan parecido. Pero todo esto tiene un riesgo evidente: el posible divorcio entre un proceso de integración europea esencialmente económico y la opinión pública europea, que puede no sólo no ver en la Unión la garantía del estado de bienestar y del modelo social del que disfruta hasta ahora en el ámbito de los países miembros sino que incluso puede atribuir al proceso de integración europea parte de la culpa en la merma de sus derechos y garantías sociales, sacrificadas en aras de los nuevos dogmas presuntamente infalibles de la unidad del mercado, de la competencia y de la competitividad.

Como ha dicho Gonzalo MAESTRO, lo preocupante es la pérdida de la autonomía de la política social que aparece ahora subordinada a la política económica. Frente al modelo social del bienestar, el denominado «welfare», estamos pasando al «workfare». Lo decían ya las conclusiones del Consejo de Barcelona del 15 y 16 de mayo de 2002, al afirmar que el modelo social europeo se basa en un buen funcionamiento de la economía, en un alto nivel de protección, educación y diálogo social, de tal manera que un Estado activo de bienestar debería alentar a las personas a trabajar, puesto que el empleo es la mejor garantía contra la exclusión social. La tensión entre protección y economía se expresa en la fórmula "hacer que trabajar sea rentable». Todo ello supone una apuesta por el «Estado mercado» en detrimento del Estado social. ${ }^{14}$

Quizá el fracaso del Tratado constitucional europeo y las dificultades que ha tenido el proceso de ratificación del Tratado de Lisboa,

13 Véanse, por ejemplo, los artículos 152, 153, 154.1, 156.1, 158, 162, 165, etc.

14 Maestro Buelga, G. «Constitución económica...», op. cit., pp. 71 y 79-80. 
junto al desapego y a la falta de interés que muchos ciudadanos europeos muestran hacia la Unión tengan mucho que ver con todo esto. En democracia el apoyo del pueblo hacia sus instituciones es esencial, porque la historia demuestra que los sistemas que no arraigan en la voluntad popular tienen los pies de barro, por muy gigantes que sean. El déficit social de la construcción europea es evidente y urge reclamar el reconocimiento de una auténtica ciudadanía social europea, compuesta por una serie de derechos con eficacia real y no teórica, que reequilibren las peligrosas tendencias que se observan en el actual proceso de construcción europea, para que los ciudadanos europeos podamos sentirnos involucrados en el proceso de integración europea y éste no se convierta en un proceso dirigido por unas élites distantes que no cuentan con el apoyo del pueblo, hacia el que los ciudadanos mostremos nuestra indiferencia cuando no nuestra hostilidad porque en algunos aspectos pueda suponer un paso atrás en vez de adelante.

Si la Unión económica va a suponer que no van a existir avances en la legislación social para toda la Unión, si incluso va a favorecer la «desregulación» en el ámbito de los Estados miembros, si no se van a salvaguardar los poderes de intervención sobre el sistema económico para compensar la hegemonía de la libertad de empresa, si no aprendemos las lecciones que nos enseñan la actual crisis económica, nos equivocaremos de rumbo. La Unión económica no puede ser utilizada para, si se me permite la expresión, «desregular», para permitir maniobras de empresas que persigan las legislaciones más favorables estableciendo, por ejemplo, centros empresariales en países miembros que posean una legislación social o fiscal menos desarrollada, o a través de la presión sobre los centros de decisión para que se produzca una competencia social a la baja, o para permitir políticas que provoquen fenómenos de «dumping social». El mensaje no puede ser «el afán de lucro por encima de todo», porque eso sería letal para el futuro de la Unión. Todo esto me recuerda aquella reflexión que hacía el gran humanista inglés Santo Tomás Moro en su famosa obra «Utopía» cuando decía aquello de:

...¿Qué añadiré de los ricos que recortan cada día un poco más el salario de los pobres, no sólo fraudulentamente sino amparados por las leyes? De esta forma, la injusticia que originaba el recompensar tan mal a los que eran más merecedores de la sociedad, se convierte, por obra de estos perversos, en justicia al ser refrendada por una ley. ${ }^{15}$

15 Libro II, capítulo IX. 
Duras palabras, tan duras como admonitorias y, sin embargo, algo de esto eso podría ocurrir en la evolución de la Unión Europea si no corregimos esta deriva. $Y$ hay señales preocupantes de que el rumbo que se quiere adoptar no es el correcto. $Y$ en relación con todo esto, me viene a la memoria la enorme polémica que provocó el conocido como proyecto de Directiva «Bolkstein», que prácticamente imponía el denominado «principio del país de origen», mediante el cual serían de aplicación a los trabajadores de un país desplazados a otro país de la Unión, las reglas y legislación laboral del país del que procedían en lugar de las vigentes en el país de acogida donde prestaban sus servicios. Para evitar que se produjeran flagrantes casos de discriminación salarial y laboral (es decir, el conocido como "dumping social») del personal desplazado a otros países de la Unión con respecto a las condiciones laborales y sociales del país de acogida, aprovechando las grandes diferencias que en este ámbito aún existen entre países miembros de la Unión (sobre todo en los de reciente incorporación, donde los salarios son mucho más bajos y las condiciones laborales más precarias), se llegó finalmente a un acuerdo de compromiso en el Parlamento Europeo, que anuló esta cláusula, que fue sustituida por la de «libertad de establecimiento y de circulación de servicios» pero sin llegar a decir expresamente que prevalecerían siempre la normativa del país de acogida, y otorgando al Tribunal de Justicia un papel relevante a la hora de interpretar el texto deliberadamente ambiguo de la Directiva. Gracias a este acuerdo de compromiso, se aprobó finalmente la Directiva 2006/123/CE del Parlamento Europeo y del Consejo, de 12 de diciembre de 2006, relativa a los servicios en el mercado interior.

Pero he aquí que el Tribunal de Justicia ha consagrado en sus últimas Sentencias una jurisprudencia que favorece claramente las libertades económicas (libertad de establecimiento, libre prestación de servicios, etc. que reflejan el concepto de la «libertad de empresa») en detrimento de los derechos sociales (derecho de huelga y de adopción de medidas de conflicto colectivo, relevancia de los convenios colectivos, etc.), con lo que no es de extrañar que muchos hayan pensado que el Tribunal, de alguna manera, ha autorizado la aplicación del «principio del país de origen» que fue eliminado del texto final de la Directiva y, en definitiva, que ha tolerado políticas de «dumping social», claramente regresivas. Me referiré en concreto a las Sentencias del Tribunal de Justicia en los conocidos casos «Viking» y «Laval», del año 2007 y «Rüffert» y «Comisión contra Luxemburgo» del año 2008. 


\section{Una perspectiva jurisprudencial}

\section{Sentencia de 11 de diciembre de 2007 (Viking Line)}

La primera de las Sentencias del Tribunal de Justicia a estudiar en este apartado es la Sentencia de 11 de diciembre de 2007, Viking Line, dictada en el asunto C-438/05 ${ }^{16}$. Se trata de la respuesta que da el Tribunal de Justicia a una cuestión prejudicial planteada, según el art. 234 del Tratado, por la Sala de lo Civil del Tribunal de Apelación de Inglaterra y Gales del Reino Unido («Court of Appeal. Civil Division. England \& Wales).

El caso era el siguiente: "Viking» era una empresa finlandesa de transporte marítimo que utilizaba transbordadores. Uno de ellos, el «Rosella» que operaba bajo pabellón finlandés hacía la ruta entre Tallin (Estonia) y Helsinki (Finlandia). Los miembros de la tripulación del «Rosella» pertenecían al sindicato finlandés de marinos (FSU), que a su vez estaba afiliado a la Federación Internacional de Sindicatos de trabajadores del transporte (ITF) con sede en Londres. La explotación del buque «Rosella» era deficitaria porque al tener que pagar a la tripulación los mismos salarios que se abonaban en Finlandia no podía competir con los buques estonios que operaban en la misma ruta y que tenían menores costes salariales, al pagar a sus trabajadores los salarios que se pagaban en Estonia. La compañía «Viking» proyectó cambiar su pabellón y registrar el buque bajo pabellón estonio o noruego, donde los costes laborales eran inferiores. El sindicato finlandés se opuso y pidió a la Federación Internacional (ITF) que, en virtud de su política de lucha contra los pabellones de conveniencia y en favor de la protección y mejora de las condiciones de trabajo de las tripulaciones de los buques bajo pabellón de conveniencia, dirigiese una circular a todos sus afiliados para que no entablaran negociaciones ni con «Viking» ni con su filial «Viking Eesti». Todos los sindicatos afiliados a la ITF están obligados a seguir esa recomendación de la Federación.

Tras expirar, según el criterio del sindicato, el acuerdo entre empresa y sindicatos aplicable al «Rosella», el sindicato finlandés anunció una huelga y exigió a la empresa que aumentara el número de trabajadores del barco y que renunciase a su proyecto de cambio de pabellón para el buque. La empresa aceptó la primera petición pero no la segunda. El sindicato anunció que sólo estaría dispuesto a renovar el acuerdo si la empresa se comprometía, con independencia del cambio de pabellón

16 STJCE de 11 de diciembre de 2007, Viking Line, C-438/05, Rec, p. I-10779. 
del «Rosella», a seguir cumpliendo el derecho finlandés y el convenio colectivo aplicable y que el eventual cambio de pabellón no implicase el despido de trabajadores del buque ni modificaciones en las condiciones de empleo sin consentimiento de los trabajadores. "Viking» consideró que el acuerdo no había expirado sino que seguía vigente y acudió a los Tribunales finlandeses para que prohibieran la huelga. En el procedimiento de conciliación, "Viking» aceptó incialmente que el cambio de pabellón no supusiera despidos, pero el sindicato siguió adelante con la convocatoria de huelga. Finalmente, la empresa «Viking», aceptó las reivindicaciones del sindicato y desistió del procedimiento judicial, prometiendo no iniciar el procedimiento de cambio de pabellón antes del 28 de febrero de 2005.

El 1 de mayo de 2005, Estonia ingresó en la Unión Europea y, como la explotación del buque seguía siendo deficitaria, "Viking» seguía teniendo la intención de abanderar el «Rosella» en Estonia. La Federación Internacional (ITF) no retiró su circular, por lo que el llamamiento que ésta dirigía a sus sindicatos miembros seguía estando operativo. Así las cosas, «Viking» presentó una demanda ante la Sala de lo Mercantil (Commercial Court) del Tribunal de la Reina (Queen's Bench Division) de la Alta Corte de Justicia de Justicia (High Court of Justice) de Inglaterra y Gales en Londres, para que se declarara que la medida de la ITF y del FSU infringía el art. 43 del Tratado de la Comunidad Europea, se ordenara la retirada de la circular y se exigiera a la FSU que no obstaculizara el ejercicio de los derechos de «Viking» con arreglo al Derecho comunitario.

El Tribunal británico de primera instancia, por Sentencia de 16 de junio de 2005, dio la razón a "Viking» indicando que las medidas de conflicto colectivo (amenaza de huelga) imponían restricciones a la libertad de establecimiento contrarias al art. 43 del Tratado y constituían restricciones ilegales a la libre circulación de los trabajadores y a la libre prestación de servicios consagradas en los arts. 42 y 43. La Federación Internacional y el sindicado finlandés recurrieron al Tribunal de Apelación (Court of Appeal) y éste, al considerar que la resolución del litigio dependía de la interpretación del derecho comunitario, decidió suspender el procedimiento y plantear al Tribunal de Luxemburgo una cuestión prejudicial en relación con este asunto. Por su parte, la Gran Sala del Tribunal de Justicia de las Comunidades Europeas, que dictó esta Sentencia, sólo admitió responder a las cuestiones planteadas por el Tribunal británico en relación con la interpretación del art. 43 del Tratado, que regula la libertad de establecimiento.

En la resolución del caso, y respecto de la primera cuestión planteada, el Tribunal de Justicia defendió que las medidas de conflicto co- 
lectivo también están afectadas por el art. 43 del Tratado, pues aunque en materia de derecho de asociación, de huelga o de cierre patronal, la Comunidad no sea competente para regular esos derechos, y aunque los Estados miembros pueden fijar sus requisitos de existencia y formas de ejercicio, deben respetar en el ejercicio de esa competencia el Derecho comunitario, y aunque el art. 137 del Tratado no se aplique a dichos derechos, una medida de conflicto colectivo como la planteada en el litigio principal sí está afectada por el art. 43 del Tratado (apartados 37, 40-41). El hecho de que el derecho a adoptar medidas de conflicto colectivo, incluido el derecho de huelga, sea un derecho fundamental que forma parte integrante de los principios generales del Derecho comunitario, no obsta para que su ejercicio pueda estar sometido a ciertas restricciones, en este caso las derivadas del art. 43 del Tratado (apartados 44-46).

A diferencia de lo que se estableció en el caso "Albany» ${ }^{17}$, donde el Tribunal de Justicia dedujo que los acuerdos celebrados en el marco de negociaciones colectivas celebradas entre interlocutores sociales para el logro de los objetivos de política social por ellos perseguidos, quedarían gravemente comprometidos si los interlocutores sociales estuviesen sujetos al antiguo art. 85-1 (hoy 81.1) del Tratado, es decir, a las normas relativas a la competencia, el Tribunal dice ahora que este razonamiento no puede extenderse a las libertades fundamentales del título III del Tratado, puesto que estas últimas disposiciones responden a requisitos de aplicación propios (apartado 53) ${ }^{18}$. Finalmente, el Tribunal recuerda que ya ha declarado que las cláusulas de los convenios colectivos no están excluidas del ámbito de aplicación de las disposiciones del Tratado relativas a la libre circulación de personas (apartado 54) ${ }^{19}$. En conclusión, el Tribunal de Justicia afirma que:

... el art. 43 CE debe interpretarse en el sentido de que, en principio, no está excluida del ámbito de aplicación de este artículo una medida de conflicto colectivo emprendida por un sindicato o una agrupación de sindicatos contra una empresa con el fin de conseguir que ésta celebre un convenio colectivo cuyo contenido puede disuadirla del ejercicio de la libertad de establecimiento. (apartado 55).

17 STJCE de 21 de septiembre de 1999, Albany, C-67/96, Rec, p. I-5751, apartados 59-60.

18 STJCE de 18 de julio de 2006, Meca-Medina y Majcen/Comisión, C-519/04 P, Rec, p. I-6991.

19 SSTJCE de 15 de enero de 1998, Schöning-Kougebetopoulou, C-15/96, Rec, p. I-47; de 24 de septiembre de 1998, Comisión / Francia, C-35/97, Rec, p. I-5325; de 16 de septiembre de 2004, Mérida, C-400/02, Rec, p. I-8471). 
La segunda cuestión que se le plantea al Tribunal es si el art. 43 del Tratado puede conferir derechos a una empresa privada que ésta puede oponer a un sindicato o a una asociación de sindicatos. El Tribunal responde que la eliminación entre los Estados miembros de los obstáculos a la libre circulación de personas y a la libre prestación de servicios correría peligro si la supresión de barreras de origen estatal pudiera ser neutralizada con obstáculos derivados de actos realizados en ejercicio de su autonomía jurídica por asociaciones y organismos que no están sometidos al Derecho público, como por ejemplo, los sindicatos (apartado 57), al igual que en la libre circulación de mercancías, las restricciones pueden tener un origen no estatal y resultar de actos realizados por personas privadas o agrupaciones de dichas personas (apartados 61-62) ${ }^{20}$, por lo que responde que «... el artículo 43 puede conferir derechos a una empresa privada que ésta puede oponer a un sindicato o a una asociación de sindicatos» (apartado 66).

En las cuestiones tercera a décima se le pregunta al Tribunal acerca de las restricciones a la libertad de establecimiento y si están o no justificadas. El Tribunal considera que una medida de conflicto colectivo planteada por el sindicato finlandés puede hacer menos interesante o incluso inútil el ejercicio por parte de Viking de su derecho al libre establecimiento pues impide que Viking y su filial Viking Eesti disfruten en el Estado de acogida del mismo trato que reciben los demás operadores económicos establecidos en ese Estado (apartado 72). También es claro que una medida de conflicto colectivo adoptada por la Federación Internacional de Sindicatos del Transporte para luchar contra los pabellones de conveniencia e impedir que los armadores abanderen sus buques en un Estado distinto del estado del que son nacionales los propietarios efectivos de esos buques, puede, cuando menos, restringir el ejercicio de Viking de su derecho al libre establecimiento (apartado 73). Es decir, que existen restricciones a la libertad de establecimiento. Ahora bien, la pregunta es si esas restricciones pueden admitirse o no. De la propia jurisprudencia del Tribunal, se deduce que se puede admitir una restricción a la libertad de establecimiento si ésta persigue un objetivo legítimo compatible con el Tratado, está justificada por razones imperiosas de interés general, es adecuada para la realización del objetivo perseguido y no va más allá del objetivo para alcanzarlo²1 (apartado 75).

20 SSTJCE de 9 de diciembre de 1997, Comisión / Francia, C-265/95, Rec, p. I-6959, apartado 30, y de 12 de junio de 2003, Schmidberger, C-112/00, Rec, p. I-5659, apartados 57 y 62 .

21 SSTJCE de 30 de noviembre de 1995, Gebhard, C-55/94, Rec, p. I-4165, apartado 37, y de 15 de diciembre de 1995, Bosman, C-415/93, Rec, p. I-4921, apartado 104. 
En el caso de la medida de conflicto colectivo emprendida por el sindicato finlandés, el Tribunal de Justicia considera que no podría aceptarse que tal medida esté comprendida en el objetivo de la protección de los trabajadores si se comprobase que los empleos o las condiciones de trabajo no estaban comprometidos o seriamente amenazados (apartado 81) y en relación a si la medida de conflicto colectivo no va más allá de lo necesario para lograr el objetivo perseguido, el Tribunal de Justicia dice que corresponde al Tribunal remitente de la cuestión examinar si el sindicato no disponía de otros medios menos restrictivos de la libertad de establecimiento para conseguir el éxito de la negociación colectiva y si el sindicato había agotado esos medios antes de emprender la medida (apartado 87).

En relación con la Federación Internacional, el Tribunal sostiene que, de los autos remitidos por el Tribunal, se deduce que dicha Federación está obligada a iniciar una acción de solidaridad cuando uno de sus miembros lo solicita en los casos de cambio de pabellón a un pabellón de conveniencia, independientemente de si el ejercicio por el propietario del buque del derecho al libre establecimiento puede o no tener consecuencias perjudiciales sobre el empleo o las condiciones de trabajo de sus asalariados, pues también actuaría en favor del derecho de negociación colectiva de los sindicatos del país del que es nacional el propietario efectivo de un buque incluso cuando el buque esté registrado en un Estado que garantice a los trabajadores una mayor protección social de la que tendrían en el primer Estado (apartado 89).

Es decir, que el Tribunal considera que las medidas de conflicto colectivo como las controvertidas en el asunto principal son restricciones en el sentido de las restricciones a la libertad de establecimiento, prohibidas por el artículo 43 del Tratado pero «... estas restricciones pueden estar justificadas, en principio, por la protección de una razón imperiosa de interés general, como la protección de los trabajadores, siempre que se compruebe que son adecuadas para garantizar la realización del objetivo legítimo perseguido y no van más allá de lo necesario para lograr este objetivo» (apartado 90).

En definitiva, de la Sentencia podemos extraer tres conclusiones claras:

1. $\left.{ }^{\circ}\right)$ Que no está excluida del ámbito de aplicación del art. 43 del Tratado una medida de conflicto colectivo emprendida por un sindicato o una agrupación de sindicatos contra una empresa con el fin de conseguir que ésta celebre un convenio colectivo cuyo contenido puede disuadirla del ejercicio de la libertad de establecimiento. 
2..$^{\circ}$ Que este artículo puede conferir derechos a una empresa privada que ésta puede oponer no sólo a organismos sometidos al derecho público, sino también a un sindicato o a una asociación de sindicatos» (apartado 66).

3..$^{\circ}$ Que las medidas de conflicto colectivo pueden suponer restricciones a la libertad de establecimiento, prohibidas en principio por el art. 43 del Tratado y que sólo podrían estar justificadas siempre que se compruebe que son adecuadas para garantizar la realización del objetivo legítimo perseguido y no van más allá de lo necesario para lograr este objetivo.

\section{Sentencia de 18 de diciembre de 2007 (Laval un Partneri)}

La segunda de las Sentencias del Tribunal de Justicia a estudiar en este apartado es la Sentencia de la Gran Sala 18 de diciembre de 2007, Laval un Partneri, dictada en el asunto C-341/0522. Se trata de la respuesta que da el Tribunal de Justicia a una cuestión prejudicial planteada según el art. 234 del Tratado por un Tribunal laboral de Suecia (Arbetsdomstolen).

El caso era el siguiente: "Laval» era una empresa con domicilio social en Riga (Letonia). Entre mayo y diciembre de 2004 desplazó a Suecia a unos treinta y cinco trabajadores para la ejecución de obras contratadas por la empresa «L\&P Baltic Bygg $A B$ », sociedad sueca de la que Laval tenía el $100 \%$ de su capital hasta finales de 2003, y en particular para la construcción de una escuela en Vaxhom. Laval, que había firmado convenios colectivos con el sindicato letón de los trabajadores de la construcción, no estaba vinculada por ningún convenio colectivo firmado con el sindicato sueco de los trabajadores de la construcción. Sin embargo, se inciaron negociaciones laborales con el sindicato sueco de la construcción para la adhesión de Laval al convenio colectivo de la construcción en Suecia. Dado que no se llegó a un acuerdo, la sección sindical $n .^{\circ} 1$ del Sindicato sueco de los trabajadores de la construcción pidió a su Sindicato que actuara para poner en práctica medidas de conflicto colectivo y que diera el correspondiente preaviso. Después, se inició un bloqueo de las obras de la escuela, consistente en impedir la entrega de mercancías en el lugar de las obras, emplear piquetes e impedir la entrada a las obras de los trabajadores letones y sus vehículos. Laval pidió la intervención de la policía, pero ésta indicó que tales me-

22 STJCE de 18 de diciembre de 2007, Laval un Partneri, C-341/05, Rec, p. I-11767. 
didas de conflicto colectivo eran lícitas en Suecia y que no podía intervenir.

Laval pidió información al Centro de enlace previsto por la Ley sueca sobre el desplazamiento de trabajadores de 9 de diciembre de 1999, Ley que realizó la adaptación al derecho sueco de la Directiva 96/71/CE del Parlamento Europeo y del Consejo, de 16 de diciembre de 1996, sobre el desplazamiento de trabajadores efectuado en el marco de una prestación de servicios. ${ }^{23}$ En la reunión de mediación entre el sindicato y Laval, el sindicato propuso a la empresa que se adhiriera al convenio colectivo colectivo de la construcción antes de tratar la cuestión salarial, con lo que hubieran cesado inmediatamente las medidas de conflicto colectivo, pero Laval se negó a hacerlo porque no le era posible conocer, con antelación, las obligaciones que se le impondrían en materia salarial. En esta situación, en diciembre de 2004, se intensificaron las medidas de conflicto colectivo contra Laval, a las que se sumó el sindicato sueco de electricistas como acción de solidaridad. Esto tuvo como efecto que las empresas suecas de instalación eléctrica no pudieron prestar servicios a Laval y los trabajadores letones tuvieron que volver a casa y no regresaron nunca a las obras. En enero de 2005, otros sindicatos suecos anunciaron acciones de solidaridad consistentes en un boicot de todas las obras emprendidas por Laval en Suecia, de modo que esta empresa ya no pudo desarrollar sus actividades en dicho país. En febrero de 2005, el Ayuntamiento de Vaxholm solicitó la resolución del contrato con Baltic para la construcción de la escuela y en marzo de 2005, Baltic fue declarada en quiebra.

En diciembre de 2004, Laval había presentado una demanda ante el Tribunal laboral sueco contra los sindicatos para que se declarara ilegal tanto el bloqueo de las obras como la acción de solidaridad que afectaban a sus proyectos y para que se pusiera fin a estas medidas y pidió una indemnización por los perjuicios sufridos. El Tribunal sueco desestimó la petición que había hecho Laval de medidas cautelares ordenando el fin de estas actividades, suspendió el procedimiento y planteó una cuestión prejudicial al Tribunal de Justicia acerca de si los artículos 12 (prohibición de la discriminación por razón de la nacionalidad) y 49 del Tratado (prohibición de las restricciones a la libertad de prestación de servicios dentro de la Comunidad para los nacionales de los Estados miembros establecidos en un país de la Comunidad que no sea el destinatario de la prestación) y la Directiva 96/71, sobre el desplazamiento de trabajadores efectuado en el marco de una

23 D.O. 1997, L 18, p. 1. 
prestación de servicios, se oponían a que las organizaciones sindicales suecas intentasen obligar, mediante medidas de conflicto colectivo, a una empresa extranjera que desplaza trabajadores a Suecia a aplicar un convenio colectivo sueco.

El Tribunal únicamente aceptó pronunciarse sobre lo relativo al art. 49 del Tratado. Frente al argumento de que el derecho a adoptar medidas de conflicto colectivo constituye un derecho fundamental excluido del ámbito de aplicación del art. 49 del Tratado y de la Directiva 96/71, puesto que el art. 137.5 del Tratado afirma que las disposiciones relativas a las medidas de conflicto colectivo no son competencia de la Comunidad, el Tribunal vuelve a recordar como en el caso Viking que el derecho a adoptar medidas de conflicto colectivo es un derecho fundamental que forma parte de los principios generales del Derecho comunitario, cuyo respeto garantiza el Tribunal de Justicia, pero que su ejercicio puede supeditarse a ciertas restricciones (apartado 91), y que el ejercicio de dichos derechos fundamentales no está excluido del ámbito de aplicación de las disposiciones del Tratado, debe conciliarse con las exigencias relativas a los derechos protegidos por el Tratado y debe ser conforme con el principio de proporcionalidad. De tal manera que hay que analizar si en el caso concreto, las medidas de conflicto colectivo constituyen una restricción a la libre prestación de servicios y si lo son, si dicha restricción está justificada.

En cuanto a la primera cuestión, el Tribunal dice que el derecho de los sindicatos de un Estado miembro de adoptar medidas de conflicto colectivo para obligar a empresas establecidas en otros estados miembros a adherirse a un convenio colectivo (en este caso el sueco) que tiene algunas cláusulas que difieren de las disposiciones legales (de Suecia) al establecer condiciones de trabajo y empleo más favorables en relación con las materias previstas en el art. 3.1. a-g de la Directiva 96/71 y a otras cláusulas no previstas en dicha disposición, puede hacer menos interesante y más difícil para dichas empresas la ejecución de obras de construcción en territorio sueco y, por tanto, constituye una restricción a la libre prestación de servicios del art. 49 del Tratado (apartado 99). Y lo mismo se puede decir de que, para conocer las cuantías del salario mínimo a abonar a sus trabajadores desplazados, dichas empresas puedan verse obligadas - mediante medidas de conflicto colectivo- a negociar por tiempo indeterminado con los sindicatos del lugar de ejecución de la prestación de servicios (apartado 100).

Como ya hemos visto, de la jurisprudencia del Tribunal se deriva que para que una restricción a la libre prestación de servicios, que es uno de los principios fundamentales de la Comunidad, pueda ser admitida, debe perseguir un objetivo legítimo compatible con el Tratado, estar jus- 
tificada por razones de interés general, ser adecuada para garantizar la realización del objetivo perseguido y no ir más allá de lo necesario para lograrlo. El Tribunal admite que el derecho a adoptar medidas de conflicto colectivo para proteger a los trabajadores del Estado de acogida frente a una eventual práctica de «dumping social» puede constituir una razón imperiosa de interés general y justificar en principio una restricción a una libertad fundamental garantizada por el Tratado (apartado 103) ${ }^{24}$. El Tribunal dice expresamente en el apartado 105 que:

Por tanto, puesto que la Comunidad tiene no sólo una finalidad económica sino también social, deben sopesarse los derechos derivados del Tratado relativos a la libre circulación de mercancías, personas, servicios y capitales, en relación con los objetivos perseguidos por la política social, entre los que figuran, en particular, como se indica en el apartado $136 \mathrm{CE}$, la mejora de las condiciones de vida y de trabajo, a fin de conseguir su equiparación por la vía del progreso, una protección social adecuada y el diálogo social.

E incluso llega a reconocer que un bloqueo iniciado por un sindicato del Estado miembro de acogida que pretende garantizar a los trabajadores desplazados en el marco de una prestación de servicios transnacional, las condiciones de trabajo y empleo fijadas en un determinado nivel está comprendido dentro del objetivo de la protección de los trabajadores (apartado 107). Sin embargo, en el caso concreto analizado, el Tribunal dice que al empresario se le puede obligar a respetar un núcleo de disposiciones imperativas de protección mínima en el Estado de acogida, según lo establecido en la Directiva, pero no ir más allá, sobre todo si tiene en cuenta que la legislación sueca no ofrecía disposiciones suficientemente precisas y accesibles para evitar que sea muy difícil para una empresa determinar sus obligaciones en materia de salario mínimo y que mediante medidas de conflicto colectivo se le pueda obligar a negociar con los sindicatos la cuantía del salario que deben abonarse a los trabajadores desplazados y a adherirse a un convenio colectivo cuyas cláusulas establecen condiciones más favorables que las derivadas de la legislación aplicable, mientras que en otras cláusulas se refieren a materias no previstas en el art. 3 de la Directiva (apartados 108-111).

24 SSTJCE de 23 de noviembre de 1999, Arblade y otros, C-369/96 y C-376/96, Rec, p. I-8453; de 15 de marzo de 2001, Mazzoleni e ISA, C-165/98, Rec, p. I-2189; de 25 de octubre de 2001, Finalarte y otros, C-49/98, C-50/98 a C-54/98 y C-68/98 a C-71/98, Rec, p.I-7831 y de 11 de diciembre de 2007, International Transport Workers' Federation y Finnish Seamens' Union —Viking Line-, C-438/05, Rec, p. I-10779. 
Otra de las cuestiones planteadas era si es compatible con el derecho comunitario la aplicación de una ley (sueca) que permite en definitiva un sistema de lucha contra el «dumping social» en virtud del cual, el prestador de servicios no tiene derecho a esperar que en el Estado miembro en el que realiza su prestación (Suecia) se tengan en cuenta de algún modo las obligaciones derivadas de los convenios colectivos a los que ya está sujeto en el Estado miembro en el que está establecido (Letonia), autorizándose las medidas de conflicto colectivo adoptadas contra empresas vinculadas por un convenio colectivo sujeto a la legislación de un Estado miembro (Letonia) del mismo modo que son lícitas las adoptadas contra empresas no vinculadas por ningún convenio colectivo.

La clave de la respuesta del Tribunal a esta cuestión es que señala en su apartado 116 que una normativa nacional que no tiene en cuenta los convenios colectivos a los que las empresas que desplazan trabajadores a Suecia ya están vinculados en el Estado miembro en el que están establecidas y les aplica el mismo trato que a las empresas nacionales que no han celebrado convenio colectivo alguno, crea una discriminación contra dichas empresas. Las normas discriminatorias deben interpretarse en sentido estricto y sólo pueden estar justificadas por razones de orden público, seguridad y salud públicas, tal y como establece el art. 46 del Tratado, pero como las finalidades perseguidas por la legislación sueca no constituyen a juicio del Tribunal una razón de orden público o de seguridad pública, las medidas previstas por la normativa sueca no pueden estar justificadas (apartado 119), por ser contrarias a los artículos 49 y 50 del Tratado (apartado 120).

\section{Sentencia de 3 de abril de 2008 (Rüffert)}

La tercera de las Sentencias del Tribunal de Justicia a estudiar en este apartado es la Sentencia de la Sala Segunda de 3 de abril de 2008, Rüffert, dictada en el asunto C-346/06. ${ }^{25}$ Se trataba de otra cuestión prejudicial, planteada con arreglo al artículo 234 del Tratado, por un Tribunal alemán de Apelación (" Oberlandesgericht Celle») acerca de la interpretación del art. 49 del Tratado (prohibiciones a la libre prestación de servicios), en relación con la Directiva 96/71/CE, reiteradamente citada, sobre el desplazamiento de trabajadores efectuado en el marco de una prestación de servicios.

25 STJCE de 3 de abril de 2008, Rüffert, C-346/06, Rec, p. I-01989. 
El caso era el siguiente: tras la correspondiente licitación, el «Land» alemán de la Baja Sajonia adjudicó en otoño de 2003 a la empresa Objekt und Bauregie $\mathrm{GmbH} \& \mathrm{Co}$. KG, cuyo administrador judicial era el Sr. Dirk Rüffert, un contrato para la construcción de la cárcel de Göttingen-Rosdorf. El contrato incluía el compromiso de observar los convenios colectivos y de pagar a los trabajadores empleados en la obra, como mínimo, el salario vigente en el lugar de ejecución, con arreglo al convenio colectivo. La empresa alemana subcontrató los servicios de una empresa polaca y en el verano de 2004 surgieron las sospechas de que dicha empresa había contratado en la obra a trabajadores por un salario inferior al previsto en el convenio. Tras el inicio de las investigaciones, tanto la empresa alemana como el Land de Baja Sajonia resolvieron el contrato de obra que habían celebrado. El Land de Baja Sajonia justificó la resolución del contrato en que la empresa alemana había incumplido lo dispuesto en el convenio colectivo. Por su parte, se dictó una resolución penal contra el principal responsable de la empresa polaca imputándole haber pagado a los 53 obreros empleados en la obra, menos de la mitad del salario mínimo fijado.

El Tribunal de Primera Instancia de Hannover declaró que el crédito que la empresa alemana tenía en virtud del contrato de obras se había extinguido por compensación por cláusula penal del $1 \%$ del valor del contrato, prevista en el art. 8.1 de la Ley del Land de Baja Sajonia sobre la contratación pública. La empresa apeló y el Tribunal de Apelación planteó la cuestión prejudicial al Tribunal de Justicia acerca si dicha actuación era compatible con la libre prestación de servicios prevista en el art. 49 del Tratado, la previsión de la Ley del Land de Baja Sajonia de obligar legalmente a la entidad adjudicadora a designar como adjudicatario de contratos públicos de obras únicamente a a las empresas que al licitar se comprometiesen por escrito a pagar a sus trabajadores, como mínimo, la retribución prevista en el convenio colectivo aplicable en el lugar de prestación de tales servicios.

Del análisis de la legislación alemana se deduce que el convenio colectivo aplicado no era un convenio colectivo de aplicación general en el sentido de lo dispuesto en la Ley alemana sobre el desplazamiento de los trabajadores, de 26 de febrero de 1996, que adaptaba al derecho alemán la Directiva 96/71 y además, sólo se aplicaba a los contratos públicos y no a los contratos privados. Según el criterio del Tribunal, la cuantía del salario previsto en el convenio no puede entenderse como cuantía de salario mínimo previsto en el art. 3 de la Directiva, que es lo que los Estados miembros pueden imponer a las empresas establecidas en otros Estados en relación con una prestación de servicios transnacional, ni puede considerarse que tal cuantía de sala- 
rio fuese una condición de empleo y de trabajo más favorable para los trabajadores en el sentido del art. 3. ${ }^{\circ}$ de la Directiva. De tal manera, que según el Tribunal, que cita expresamente la Sentencia del caso «Laval un Partneri», esa disposición no podía interpretarse «en el sentido de que permite al Estado miembro de acogida supeditar la realización de una prestación de servicios en su territorio al cumplimiento de condiciones de trabajo y empleo que vayan más allá de las disposiciones imperativas de protección mínima» (apartado 33). Así que, sin perjuicio de la facultad de las empresas establecidas en otros Estados miembros de adherirse voluntariamente en el Estado de acogida a un convenio de trabajo eventualmente más favorable para su personal desplazado, «el grado de protección que debe garantizarse a los trabajadores desplazados al territorio del Estado miembro de acogida se limita, en principio, al previsto en el artículo 3, apartado 1, párrafo primero, letras a) a g) de la Directiva 96/71, salvo que dichos trabajadores ya disfrutaran, en virtud de la legislación o de convenios colectivos en el Estado miembro de origen, de condiciones de trabajo y empleo más favorables en relación con las materias previstas en dicha disposición» (apartado 34).

Esto no ocurría en este caso y, según el Tribunal, que sigue la argumentación del Abogado General (Sr. Y. Bot), obligar a los adjudicatarios de contratos públicos de obras y de manera indirecta a los subcontratistas a aplicar la retribución mínima prevista en el Convenio, supone imponer a los prestadores de servicios establecidos en otro Estado miembro (en el que los salarios son inferiores), una carga económica adicional que puede impedir, obstaculizar o hacer menos interesante la ejecución de sus prestaciones en el Estado miembro de acogida, lo que puede constituir una restricción a la libre prestación de servicios prohibida por el art. 49 del Tratado (apartado 37).

En cuanto al argumento de que tal medida pudiese estar justificada por el objetivo de la protección de los trabajadores, el Tribunal lo rechaza pues ese convenio sólo se aplica a los contratos públicos y no a los privados y además no es de aplicación general y dice que no se entiende que la protección que resulta de la cuantía del salario, por encima del salario mínimo, sólo le resulte necesaria a un trabajador del sector de la construcción cuando éste esté empleado en un contrato público de obras y no cuando lo está en un contrato privado (apartados 39-40). Tampoco acepta el Tribunal que dicha restricción esté justificada por el objetivo de garantizar la protección de la organización autónoma de la vida profesional mediante sindicatos, ni por la razón imperiosa de interés general de evitar un riesgo de perjuicio grave para el equilibrio financiero del sistema de Seguridad social. Por todo ello, 
considera que la Directiva 96/71, interpretada a la luz del art. 49 del Tratado, se opone a tal tipo de medidas legales (apartado 43).

\section{Sentencia de 19 de junio de 2008 (Comisión contra Luxemburgo)}

La cuarta y última Sentencia del Tribunal de Justicia a la que voy a referirme aquí es la Sentencia de la Sala Primera de 19 de junio de 2008, Comisión / Luxemburgo, en el asunto C-319/06. ${ }^{26}$ Se trata de un recurso por incumplimiento interpuesto, según lo previsto por el art. 226 del Tratado, por la Comisión Europea contra el Ducado de Luxemburgo, por incumplimiento de las obligaciones derivadas de la Directiva 96/71/CEE del Parlamento Europeo y del Consejo, sobre el desplazamiento de trabajadores efectuado en el marco de una prestación de servicios, así como de los artículos 49 y 50 del Tratado. En definitiva, lo que la Comisión denuncia es que Luxemburgo no realizó correctamente la adaptación de la Directiva 96/71 a su normativa nacional mediante su Ley de 20 de diciembre de 2002 y el Tribunal le da la razón a la Comisión.

Por lo que interesa a este trabajo, únicamente citaré aquí cómo el Tribunal vuelve a insistir en que la libre prestación de servicios, como principio fundamental del Tratado sólo puede limitarse mediante normas justificadas por razones imperiosas de interés general y que se apliquen a cualquier persona o empresa que ejerza una actividad en el territorio del Estado miembro de acogida, en la medida en que dicho interés no quede salvaguardado por las normas a las que está sujeto el prestador en el Estado miembro en el que está establecido (apartado 43). Y en cuanto a la protección de los salarios de los trabajadores desplazados, el Tribunal vuelve a dejar claro que el art. 3.1.1.a de la Directiva 96/71, pretende circunscribir la facultad de intervención de los Estados miembros, en lo que a salarios se refiere, a las cuantías del salario mínimo (apartado 47).

Finalmente, no me queda ya sino dejar constancia de cómo el Tribunal se reafirma en algunas de sus tesis y deja claro que la reserva de orden público constituye una excepción al principio fundamental de la libre prestación de servicios que debe ser interpretada restrictivamente; que su alcance no puede ser determinado unilateralmente por los Estados miembros (apartado 30); que sólo puede invocarse en caso de que exista una amenaza real y suficientemente grave que afecte a un inte-

26 STJCE de 19 de junio de 2008, Comisión / Luxemburgo, C-346/06, Rec, p.I04323. 
rés fundamental de la sociedad (apartado 50) y que, en el caso de las disposiciones referentes a los convenios colectivos de trabajo, es decir, las que regulan su elaboración y aplicación, nada justifica que éstas puedan subsumirse "per se» y sin más precisión en el concepto de orden público (apartado 65).

En definitiva, que la Sentencia de 19 de junio viene a reafirmarse en las tesis más restrictivas del Tribunal en cuanto a las excepciones aplicables a las libertades económicas instauradas por el Tratado, dando clara prioridad a dichas libertades frente a una interpretación más favorable a una protección más eficaz de los derechos sociales en el marco de la Unión Europea.

\section{Reflexión final}

De todo lo que hemos visto hasta ahora, parece deducirse que, en caso de conflicto entre la libertad de establecimiento (que no es más que una concreción del derecho de libertad de empresa en el ámbito comunitario) y los derechos sociales, prevalece la libertad de establecimiento con carácter general salvo en los casos excepcionales que ha admitido el Tribunal, excepciones que, como hemos visto, viene interpretando restrictivamente.

Como han puesto de manifiesto muchos autores, el peligro de todo esto es la tendencia que en los últimos tiempos están mostrando algunas instituciones comunitarias (y hay claros ejemplos de ello, como el proyecto inicial de Directiva Bolkestein, algunas afirmaciones del Libro Verde para la Modernización del Derecho del Trabajo, etc.) y que parece estar siendo apuntalada por la jurisprudencia del Tribunal de Justicia, de primar de manera excesiva las libertades económicas por encima de los derechos sociales. En otras palabras, el difícil y siempre inestable equilibro entre libertades económicas y derechos sociales, parece que está siendo sustituido por un claro desequilibrio en favor de las primeras, con el peligro que ello supone para la consolidación de una auténtica Europa social y sus posibles consecuencias, entre las que se encuentra el creciente desapego de la ciudadanía hacia un modelo de Unión Europea que muchas veces no parece ser capaz de hacer reales las esperanzas y los anhelos puestas en ella y que corre el serio riesgo de defraudar las expectativas creadas. Es nuestra obligación estar vigilantes y luchar para corregir estos posibles desequilibrios. Ahora es tiempo de luchar por lo que creemos justo, para que no tengamos luego que lamentarnos, cuando ya sea tarde. 


\section{Bibliografía}

Adrián Arnálz, A.J. "Las Sentencias del Tribunal de Justicia de las Comunidades Europeas "Viking' y "Laval" (2007) y "Comisión c. Luxemburgo" (2008) y la prevención del "dumping" social en la Unión Europea». Información laboral. Jurisprudencia. 2008, n. ${ }^{\circ}$, pp. 2-13.

Albertí Rovira, E. "La Constitución económica. Tendencias a los veinte años de la Constitución». En Trujillo, G. et al. La experiencia constitucional. Madrid: Centro de Estudios Políticos y Constitucionales, 2000, pp. 125-158.

AlberTí Rovira, E. «La constitución económica de 1978: reflexiones sobre la proyección de la Constitución sobre la economía en el XXV aniversario de la Constitución española». Revista Española de Derecho Constitucional. 2004, n. ${ }^{\circ} 71$, III, pp. 123-160.

ANDREONI, A. / VenEZIANI, B. Libertà economiche e diritti sociali dell'Unione europea dopo le sentenze Laval, Viking, Rüffert e Lussemburgo. Roma: Ediesse, 2009.

ARAgón ReYes, M. "Constitución económica y libertad de empresa». En IGLESIAS PRAdA, J.L. (coord.). Estudios jurídicos en homenaje al profesor Aurelio Menéndez. Madrid: Civitas, 1996. Vol. 1, pp. 163-180.

Aragón Reyes, M. Libertades económicas y Estado Social. Madrid: Mc GrawHill, 1996.

Ballestero, M.V. «Le sentenze Viking e Laval: La Corte di giustizia "bilancia" il diritto di sciopero». Lavoro et diritto. 2008, vol. 22, n. ${ }^{\circ} 2$, pp. 371-392.

Baquero Cruz, J. "La protección de los derechos sociales en la Comunidad Europea tras el Tratado de Amsterdam». Revista de Derecho Comunitario Europeo. 1998, n. ${ }^{\circ} 4$, pp. 639-666.

Baylos Grau, A. «El espacio supranacional de ejercicio del derecho de huelga y la restricción legal de sus capacidades de acción». Revista de derecho social. 2008, n. ${ }^{\circ} 41$, pp. 123-143.

Brino, V. «Gli equilibrismi della Corte di Giustizia: il caso Rüffert». Rivista italiana di diritto del lavoro. 2008, II, pp. 479-486.

Cabo Martín, C. de. «Constitucionalismo del Estado social y Unión Europea en el contexto globalizador». Revista de Derecho Constitucional Europeo. 2009, n. $^{\circ} 11$.

Cancio Melí́, J. «La Constitución económica: promesas incumplibles». Revista Jurídica de la Universidad Autónoma de Madrid. 2002, n. 7, pp. 49-101.

CAntARO, A. «El declive de la Constitución económica del Estado Social». En García Herrera, M.A. (dir.). El constitucionalismo en la crisis del Estado Social. Bilbao: Universidad del País Vasco / Euskal Herriko Unibertsitatea, 1997, pp. 153-178.

CAntARO, A. I/ secolo lungo. Lavoro e diritti sociali nella storia europea. Roma: Ediesse, 2006.

CARABelli, U. "Note critiche a margine delle sentenze della Corte di Giustizia nei casi Laval e Viking». Giornale di diritto del lavoro e di relazioni industriali. 2008, vol. 30, n. ${ }^{\circ} 117$, pp. 147-167.

CARUSO, B. "La integración de los derechos sociales en el espacio social supranacional y nacional; primeras reflexiones sobre los casos "Laval" y "Vi- 
king"». Relaciones laborales: Revista crítica de teoría y práctica. 2008, n. ${ }^{\circ}$ 2, pp. 159-186.

CASSESE, S. "La costituzione economica europea». Rivista italiana di Diritto Pubblico Comunitario. 2001, pp. 907 y ss.

Chaumette, P. «Les actions collectives syndicales dans le maillage des libertés communautaires des enterprises, CJCE 11 décembre 2007, ITF et CJCE 18 décembre 2007, Laval». Droit social. 2008, n. ${ }^{\circ}$ 2, pp. 210-220.

Cidoncha Martín, A. La libertad de empresa. Madrid: Civitas, 2006.

DAVIES, A.C.L. "One step forward, two steps back? The Viking and Laval Cases in en the ECJ». Industrial Law Journal. 2008, pp. 126-148.

Defossez, A. "Détachement des travailleurs, ordre public et dumping social, suite et certainement pas fin...». Revue de la Faculté de droit de l'Université de Liège. 2008, pp. 602-612.

DONNETTE, A. «À propos d'une rencontre mouvementée entre droit social et droit du marché. Les arrêts Viking, Laval, Rüffert et Luxembourg». Revue des affaires europeennes. 2007-2008, n. ${ }^{\circ}$ 2, pp. 341-358.

EmBID IRUjo, A. Derechos económicos y sociales. Madrid: Iustel, 2009.

Ferreiro Regueiro, C. «Los desplazamientos transnacionales tras el asunto "Rüffert". Relaciones laborales. Revista crítica de teoría y práctica. 2009, n. ${ }^{\circ} 14$, pp. 89-102.

Fotinopoulou BASURKo, O. «El asunto "Viking line": un litigio que va más allá de la encrucijada entre las libertades económicas comunitarias y el derecho de huelga». Tribuna social: Revista de seguridad social y laboral. 2009, n. ${ }^{\circ} 217$, pp. 40-58.

FreitAS DA COSTA, C. "Libre prestation des services ("Rüffert")». Revue du droit de l'Union Européenne, 2008, n. ${ }^{\circ}$ 3, pp. 612-619.

GAMBINo, S. Stato e diritti sociali fra costituzioni nazionali e Unione europea. Ligouri: Napoli, 2009.

García Alcorta, J., La limitación de la libertad de empresa en la competencia, Barcelona: Atelier, 2008.

García Herrera, M.A. (dir.). El constitucionalismo en la crisis del Estado social. Bilbao: Universidad del País Vasco / Euskal Herriko Unibertsitatea, 1997.

García-Perrote Escartín, I. / Mercader Uguina, J.R. «Controvertidos pronunciamientos del Tribunal de Justicia de las Comunidades Europeas sobre desplazamiento transnacional de trabajadores: los asuntos Viking, Laval y Rüffert». Justicia laboral: Revista de Derecho del Trabajo y de la Seguridad Social. 2008, n. ${ }^{\circ} 34$, pp. 5-11.

García Vitoria, I. La libertad de empresa: ¿un terrible derecho? Madrid: Centro de Estudios Políticos y Constitucionales, 2008.

GARDE, A. / MAHÉ, S. «L'affaire Viking: dans quelle mesure une action syndicale collective peut-elle constituer un obstacle à la liberté d' etablissement?». Revue du marche commun et de l'Union Européenne. 2009, n. ${ }^{\circ}$ 525, pp. 97-106.

GIUBBonl, S. Diritti sociali e mercato. La dimensione dell'integrazione europea. Bologna: II Mulino, 2003.

Guamán Hernández, A. "La sumisión del derecho de huelga a la libertad de establecimiento comunitaria: el caso Viking Line. Comentario a la STJCE de 
11 de diciembre de 2007, Viking Line, C-438/05 (TJCE 2007, 357)». Aranzadi Social. 2007, n. ${ }^{\circ}$ 5, pp. 1326-1337.

Guamán HeRnÁndez, A. "Los límites de la acción sindical en las situaciones de desplazamiento transnacional de trabajadores». Aranzadi Social. 2007, n. ${ }^{\circ} 84$, pp. $1-8$.

Guamán HeRnÁndez, A. «Desplazamiento transnacional de trabajadores y convenios colectivos (Parte Tercera): el caso Rüffert». Aranzadi Social. Revista Doctrinal. 2008, vol. I, n. ${ }^{\circ}$ 5, pp. 47-59.

Guamán Hernández, A. "De nuevo sobre la ley aplicable en los supuestos de desplazamiento temporal de trabajadores: el caso Laval». Relaciones laborales: Revista crítica de teoría y práctica. 2008, n. ${ }^{\circ} 2$, pp. 187-212.

LANDA ZAPIRAIN, J.P. "Una nueva encrucijada para el Derecho del Trabajo: la compatibilidad del ejercicio de los derechos colectivos de la acción sindical con el respeto a las libertades fundamentales del mercado interior comunitario. Comentario de las Sentencias de la Gran Sala del TJE de 11/12/2007 (A. Viking) y de 18/12/2007 (Laval)». Relaciones laborales: Revista crítica de teoría y práctica, 2008, n. ${ }^{\circ} 1$, pp. 481-506.

Larrazabal Basañez, S., "Constitución económica, Democracia social, Innovación y Cultura Económica del Cooperativismo Vasco». Boletín de la Asociación Internacional de Derecho Cooperativo. 2009, n. ${ }^{\circ} 43$, pp. 179191.

Lo FARO, A. "Diritto sociali e libertà economiche del mercato interno: considerazioni minime in margine ai casi Laval e Viking». Lavoro e diritto. 2008, vol. 22, n. ${ }^{\circ}$, pp. 63-96.

Maestro Buelga, G. "Constitución económica y derechos sociales en la Unión Europea». Revista de Derecho Comunitario Europeo. 2000, n. ${ }^{\circ}$ 7, pp. 123-154.

Maestro Buelga, G. «Estado de mercado y Constitución económica: algunas reflexiones sobre la crisis constitucional europea». Revista de Derecho Constitucional Europeo. 2007, n. ${ }^{\circ}$ 8, pp. 43-73.

Maestro Buelga, G., "Constitución económica y modelo social europeo». Boletín de la Academia Vasca de Derecho. 2008, n. ${ }^{\circ} 15$, pp. 49-82.

Maestro Buelga, G. «El Tratado de Lisboa y la Constitución económica». Revista de Derecho Constitucional Europeo. 2008, n. ${ }^{\circ}$ 9, pp. 37-68.

Maestro Buelga, G., "Constitución económica y modelo social europeo». Boletín de la Academia Vasca de Derecho. 2008, n. ${ }^{0}$ 15, pp. 49-82.

MiglIORINI, S. «Delocalizzazioni di imprese e azioni sindacali secondo la sentenza Viking». Rivista di diritto internazionale. 2008, n. ${ }^{\circ}$ 3, pp. 776-788.

NovITZ, T. "The right to strike and re-flagging in the European Union: free movement provisions and human rights». Lloyd's Maritime and Commercial Law Quarterly. 2006, pp. 242-256.

Polares Maduro, M. «L'equilibre insaissible entre la liberté économique et les droits sociaux dans l'Union Européenne». In L'Union Européenne et les droits de l'homme. Bruxelles, Bruylant, 2001, pp. 465 y ss.

Quadra-SalCedo JaninI, T. de la. "TJCE. Sentencia de 18.12.2007, Laval, C-341/05. Libre prestación de servicios. Desplazamiento de trabajadores. La supuesta legalización del dumping social en el interior de la Unión Euro- 
pea». Revista de Derecho Comunitario Europeo. Año n. ${ }^{\circ} 12$, n. ${ }^{\circ} 31,2008$, pp. 835-848.

REICHT, N. "“Widening" vs. "deepening" the European Union: free movement vs. Social rights in the Laval case before the ECJ». En Blockmans S. / PreCHAL, S. (coords.). Reconciling the deepening and widening of the European Union. Asser Institute Colloquium on European Law, session 36, 29 september 2006, pp. 29-57.

REICHT, N. «Free Movement v. Social Rights in an Enlarged Union: The Laval and Viking Cases before the European Court of Justice». German Law Journal. 2008, vol. 9, n. ${ }^{\circ}$ 2, pp. 125-160.

ReNTERO JOVER, J. "Y ahora, Rüffert». (Comentario a la STJCE de 3 de abril de 2008)». Revista de Derecho Social. 2008, n. 42, pp. 117-123.

ROBIN-OLIVIER, S. «Libre prestation des services, marchés publics et régulation sociale: le droit européen privilégie la concurrence fondée sur le coût du travail. CJCE, 3 avril 2008, Rüffert, affaire C-346/06». Revue trimestrelle de droit européen. 2008, vol. 44 , n. ${ }^{\circ} 3$, pp. 485-495.

RoDièRE, P. «Les arrêts Viking et Laval, le droit de grève et le droit de négociation collective». Revue trimestrielle de droit europeen. 2008, vol. 44, n. ${ }^{\circ}$, pp. 47-66.

RodríGuez-PIÑERo Bravo-FerReR, M. "El caso "Rüffert": ¿una constitucionalización del "dumping" social?». Relaciones laborales. Revista crítica de teoría y práctica. 2008, n. ${ }^{\circ}$ 2, pp. 213-244.

SaUteR, W. "The economic constitution of the European Union». Columbia Journal of European Law. 1998, n. ${ }^{\circ} 4$, pp. 27 y ss.

SCIARRA, S. "Viking" y "Laval": Huelga, Convenio Colectivo y libertades fundamentales en el Mercado Europeo». Relaciones laborales: Revista crítica de teoría y práctica. 2008, n. ${ }^{\circ} 2$, pp. 137-158.

SCIARRA, S. "Viking e Laval: diritti colletivi e mercato nel recente dibattito europeo». Lavoro e diritto. 2008, vol. 22, n. ${ }^{\circ} 2$, pp. 245-272.

Streit, M.E. / Mussler, W. "The economic constitution of the European Community: From Rome to Maastricht». European Law Journal. 1995, n. ${ }^{\circ} 1$.

THOMAS, S. «Libre prestation de services, travailleurs détachés et droit de recourir à l' action collective (arrêt "Laval")». Revue de droit de l'Union Européenne. 2008, n. ${ }^{\circ} 1$, pp. 181-192.

ThOMAS, S. "Liberté d'établissement et droit de recourir à l'action collective (arrêt "Viking")». Revue de droit de l'Union Européenne. 2008, n. 1, pp. $193-200$.

ToRnOS MAS, J. (coord). Ordenación económica. Valladolid: Lex Nova, 2008.

URIARTE TORREALDAY, R. «Propiedad, libre empresa y trabajo: los derechos económicos en la Constitución español y en el proyecto constitucional europeo». Revista de Derecho Constitucional Europeo. 2005, n. ${ }^{\circ} 4$, pp. 333-372.

Viera Álvarez, Ch. La libertad de empresa y algunos límites desde la perspectiva del Estado Social. Memoria académica para la obtención del Diploma de Estudios Avanzados por la Universidad de Deusto, noviembre de 2009 (inédita). 


\section{Jurisprudencia seleccionada del Tribunal de Justicia de la Unión Europea en materia de libertades económicas y derechos sociales}

1. Aplicabilidad del Tratado, libre circulación de personas y actividades sindicales

SSTJCE de 15 de enero de 1998, Schöning-Kougebetopoulou, C-15/96, Rec, p. I-47.

STJCE de 24 de septiembre de 1998, Comisión / Francia, C-35/97, Rec, p. I-5325.

STJCE de 21 de septiembre de 1999, Albany, C-67/96, Rec, p. I-5751.

STJCE de 12 de septiembre de 2000, Pavlov y otros, C-180/98 a C-184/98, Rec, p. I-6451.

STJCE de 21 de septiembre de 2000, van der Woude, C-222/98, Rec, p. I-7111.

STJCE de 16 de septiembre de 2004, Mérida, C-400/02, Rec, p. I-8471.

STJCE de 18 de julio de 2006, Meca-Medina y Majcen/Comisión, C-519/04 P, Rec, p. I-6991.

2. Derechos fundamentales entendidos como interés legítimo que pueden justificar restricciones de obligaciones impuestas por el derecho comunitario

STJCE de 30 de noviembre de 1995, Gebhard, C-55/94, Rec, p. I-4165. STJCE de 15 de diciembre de 1995, Bosman, C-415/93, Rec, p. I-4921.

STJCE de 9 de diciembre de 1997, Comisión / Francia, C-265/95, Rec, p. I-6959.

STJCE de 12 de junio de 2003, Schmidberger, C-112/00, Rec, p. I-5659.

STJCE de 14 de octubre de 2004, Omega, C-36/02, Rec, p. I-9609.

3. Extensión de la legislación o de los convenios colectivos relativos a toda persona que realice un trabajo por cuenta ajena en el territorio de un Estado miembro, con independencia del Estado de establecimiento del empresario, siempre que no vayan más allá de garantizar el objetivo perseguido: la protección de los trabajadores desplazados

STJCE de 3 de febrero de 1982, Seco y Desquenne \& Giral, C-62/81 y 63/81, Rec, p. I-223.

STJCE de 23 de noviembre de 1999, Arblade y otros, C-369/96 y C-376/96, Rec, p. I-8453. 
STJCE de 14 de enero de 2002, Portugaia Construções, C-164/99, Rec, p. I-787.

STJCE de 14 de abril de 2005, Comisión /Alemania, C-341/02, Rec, p. I-2733.

4. Derecho a adoptar medidas de conflicto colectivo para proteger a los trabajadores del Estado de acogida frente a una eventual política de «dumping social», como razón imperiosa de interés general que justifique restricciones a una libertad fundamental garantizada por el Tratado

STJCE de 23 de noviembre de 1999, Arblade y otros, C-369/96 y C-376/96, Rec, p. I-8453.

STJCEE de 15 de marzo de 2001, Mazzoleni e ISA, C-165/98, Rec, p. I-2189.

STJCE de 25 de octubre de 2001, Finalarte y otros, C-49/88, C-50/88, C-52/98 a C-54/98 y C-68/98 a C-71/98, Rec, p. I-7831.

5. Conflicto entre las libertades comunitarias de establecimiento y de circulación de servicios y los derechos sociales de los trabajadores de los Estados miembros:

STJCE de 11 de diciembre de 2007, Viking Line, C-438/05, Rec, p. I-10779.

STJCE de 18 de diciembre de 2007, Laval un Partneri, C-341/05, Rec, p. I-11767.

STJCE de 3 de abril de 2008, Rüffert, C-346/06, Rec, p. I-01989.

STJCE de 19 de junio de 2008, Comisión / Luxemburgo, C-319/06, Rec, p. I-04323. 